\title{
LES FEMMES ILLUSTRES (1642) DE MADELEINE DE SCUDÉRY: TRADUÇÃO DO DISCURSO “SAFO A ERINA”
}

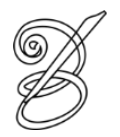 \\ André Luís Leite de MENEZES* \\ Universidade Federal de Santa Catarina, Brasil \\ Marie-Hélène Catherine TORRES** \\ Universidade Federal de Santa Catarina, Brasil
}

RECEBIDO EM: 13 de agosto de 2019

ACEITO EM: 12 de dezembro de 2019

PUBLICADO EM: janeiro 2020

adeleine de Scudéry (1607-1701) faz parte de um panteão de autoras francesas
do século XVII - Ninon de Lenclos (1620-1705), Madame de Sévigné (1626-
1696), Madame de La Fayette (1634-1693), Madame d'Aulnoy (1651-1705), apenas para citar algumas -, que, apesar de terem deixado um vasto e importante legado literário, são ainda pouco conhecidas em solo brasileiro ${ }^{1}$, já que boa parte de suas obras permanece inacessível a um público-leitor de língua portuguesa. Comentando a respeito do ofício do escritor, Rachel de Queiroz disse, em uma entrevista², que para cada escritor há uma razão diferente de escrever e completou: "no meu caso, num certo sentido é o desejo interior de dar um testemunho do meu tempo, da minha gente e principalmente de mim mesmo: eu existi, eu sou, eu pensei, eu senti, e eu queria que você soubesse". Nesse sentido, retomando as palavras da escritora e tradutora nordestina, podemos então nos indagar se a tradução não seria uma forma de ouvir esses testemunhos de mulheres do passado, escritos silenciados ao longo da história, e, também, uma maneira de se (re)pensar o cânone literário, muitas vezes androcêntrico e excludente.

Conforme apontou André Lefevere (1992), a tradução, longe de ser uma atividade "neutra", de fato reproduz demandas sociais e históricas e tanto influencia a sedimentação de velhos paradigmas, ideias, conceitos e gêneros literários, como os desconstrói, gerando novas perspectivas e outras (re)leituras. Para Olga Castro (2017), caberia aos Estudos da Tradução questionar o que se traduz, quem traduz e com quais critérios o faz, buscando, assim, diminuir 
atitudes discriminatórias ligadas ao gênero e, consequentemente, enriquecendo grandemente o campo da tradução e da literatura. No que se refere às obras de autoria feminina, ainda segundo Castro (2017, p. 230), não se trata de colaborar com as mulheres "pelo fato de que sejam mulheres (constituindo uma atitude paternalista), mas porque suas obras são relevantes, embora essa relevância permaneça oculta por não se adequar aos critérios estipulados pelo cânone patriarcal”.

Voltando a atenção à escritora Madeleine de Scudéry, vale dizer, grosso modo, que é uma das mais prolíficas autoras da história literária francesa. Seu romance, Artamène ou le Grand Cyrus (1649-1653), publicado em dez volumes, é considerado um dos mais longos romances franceses de todos os tempos. Nascida em 15 de novembro de 1607 na comuna de Le Havre, situada na região da Normandia, Scudéry fez bastante sucesso nos salões parisienses - entre os quais vale mencionar o célebre salão da Marquesa de Rambouillet (1588-1665) - que eram voga na sociedade francesa seiscentista. Proveniente de uma família aristocrática normanda sem muita importância e órfã desde muito cedo, ela contaria com a colaboração de seu irmão mais velho, Georges de Scudéry (1601-1667), que se encarregaria

224 de assinar a maioria das obras da irmã, seguindo os costumes daquele tempo, que impunham o anonimato e a discrição às mulheres escritoras. Toda a instrução dos dois irmãos fora dada por intermédio de um tio eclesiástico com quem os Scudéry ficariam após a morte dos pais, e que lhes permitiria o estudo das artes, da leitura, das línguas e da filosofia.

Madeleine nunca chegou a se casar, optando pelo celibato, que pode ser compreendido como uma forma de liberdade para aquela época, já que as mulheres casadas eram consideradas propriedade dos maridos. Não é à toa que Madeleine seria lembrada posteriormente pela crítica como uma das mais influentes "preciosas" de seu tempo, isto é, mulheres associadas ao preciosismo, que segundo Carla Cristina Garcia (2011, p. 32) se constituiu como um "fenômeno complexo que se apresenta ao mesmo tempo como um modelo de comportamento, uma corrente literária, um movimento sobretudo feminino que afrontava temas que iam muito além do âmbito da cultura", colocando a mulher no centro do debate e buscando uma condição intelectual igualitária para o sexo feminino. É em seu romance, Clélie, histoire romaine (1654-1660), que se encontra o Carte de Tendre ou Carte du Pays de Tendre [O mapa do País da Ternura], uma espécie de representação topográfica e alegórica do amor seguindo os ideais do preciosismo e inspirado nos códigos da cavalaria medieval, retratando a mulher como um ser perfeito e inalcançável, mostrando os vários 
obstáculos (rios, desertos e montanhas) que o homem deve superar para alcançar o amor espiritual e pleno.

Apesar de ter sido premiada por importantes instituições literárias - pela Academia Francesa em 1671 e pela Academia de Ricovrati em 1684 -, Madeleine (entre outras escritoras) foram bastante ridicularizadas por literatos famosos de sua época (Molière, Furetière e Boileau), provavelmente incomodados pela forte presença feminina que dominava o cenário das Letras no século XVII. Seria apenas recentemente, contudo, a partir de novas perspectivas feministas, que a obra de Madeleine de Scudéry passaria a ser reavaliada pela crítica. Não mais taxada de "preciosa pedante" ou como um simples "fenômeno de salão", sua fortuna crítica passa a ser examinada sob aspectos filosóficos, teológicos e epistemológicos. Oferecendo uma rica análise das virtudes e dos vícios da sociedade aristocrática de sua época, sempre com um recorte de gênero, enfatizando-se a condição feminina, criticando, por exemplo, os abusos de poder na relação entre os homens e mulheres, especialmente na prática de estupro e casamento forçado ${ }^{3}$, a obra de Scudéry nos fornece uma tradução valiosa dos costumes e pensamentos daquele período histórico a partir de uma perspectiva feminina. A escritora morre em 2 de junho de 1701 com quase 94 anos de idade, o que era bastante incomum, considerando os padrões de vida da época. Deixou uma série de obras, dos mais diversos gêneros literários: romance, novela, diálogo, oratória, carta.

O trecho que aqui se propõe traduzir faz parte de Les femmes illustres, ou les harangues hérö̈ques, obra que ganhou sua primeira publicação em 1642 na França — edição que hoje pode ser acessada por meio do acervo digital da Biblioteca Nacional Francesa (Gallica) - e a qual apresenta uma coletânea de vinte discursos imaginários, chamados de harangues, pronunciados por importantes figuras femininas da Antiguidade, silenciadas ao longo da história, como Cleópatra, Sisigambis, Sofonisba, Pórcia, Berenice, Zenóbia, Lucrécia, entre outras. Segundo o Dictionnaire de l'Académie Française ${ }^{4}$, o vocábulo harangue remontaria ao termo italiano ar(r)inga — que no século XV significava "discurso público" —, provavelmente formado a partir da palavra $\operatorname{ar}(r)$ ingo, que, por sua vez, se referia a uma "arena", "local de encontro". O trecho ora escolhido trata-se da vigésima e última arenga da coletânea, em que Safo, a célebre poetisa grega - que, aliás, era também o pseudônimo de Scudéry nos salões e meios mundanos - exorta sua amiga e poetisa Erina a se dedicar às artes, à literatura e à ciência. A originalidade dessa arenga, em particular, reside no fato de Scudéry apresentar uma Safo que não é mais passiva, simples objeto de discurso, aquela que sofre por amor ou lamenta a ausência do amante, como se lê nos poemas 
epistolares de Heroides, escritos por Ovídio, rompendo com essa tradição literária, tornandose, então, o próprio assunto do discurso, configurando-se como uma narradora autodiegética que se fundamenta em processos retóricos (arte tradicionalmente masculina) para expressar sua coragem, sua eloquência, seu orgulho e sua ambição, num grande apelo em favor das conquistas femininas.

Desse modo, vale enfatizar a relevância de um texto que, apesar de ter sido produzido há mais de 370 anos, continua a abordar questões atuais e instigantes. Afinal, as mulheres do século XXI ainda lutam por reivindicações igualitárias e por melhores indicadores nas áreas social, educacional, política e econômica. Assim, lido a partir desse novo contexto, o texto que se apresenta a seguir configurar-se-ia antes como um manifesto, uma intervenção política, um grito embrionário de empoderamento feminino e, acima de tudo, uma celebração da mulher.

O discurso fictício proferido por Safo ofereceu muitos desafios tradutórios não apenas devido à escrita do francês arcaico, mas também por suas diversas técnicas de argumentação, pelas longas frases repletas de conjunções subordinativas, pela ausência absoluta de parágrafos, pelos poemas com rimas emparelhadas e cruzadas e pelas palavras de múltiplas acepções, tais como esprit, mérite e inclination. Com relação ao vocábulo amie, por exemplo, vale aludir à sua dupla acepção certamente ambígua que há na leitura do texto em francês, já que a palavra pode ser usada para se referir tanto a "amiga" como "amante", o que não acontece no português, em que "amiga" elimina uma importante possibilidade de interpretação que poderia sugerir uma possível intimidade amorosa entre as duas mulheres.

Na medida do possível, foi necessário adotar certas mudanças sintáticas de modo a manter a escrita em português claro e compreensível. Apesar de não ter sido encontrada qualquer tradução em português do Brasil, foi de grande ajuda a consulta de duas traduções para o inglês, que forneceram importantes possibilidades de leitura. O trecho em questão não possui separações de parágrafos. Contudo, visando facilitar a leitura, optou-se em dividir o texto seguindo o exemplo das traduções para o inglês consultadas ${ }^{5}$. Assim, pôde-se colocar o texto em francês e o texto traduzido em tabelas, lado a lado, possibilitando ao leitor um cotejamento entre as duas escritas. Também foi indispensável, em algumas passagens, recorrer a notas de fim de página, a fim de elucidar certas referências não tão evidentes.

Por fim, vale comentar ainda acerca da tradução do pronome sujeito vous, que em francês é usado para se referir a um "tu"/“você" formal ou plural. Antes, porém, é necessário compreender de que forma o discurso de "Safo a Erina" está estruturado. Primeiramente 
apresenta-se um argumento introdutório que informa o leitor sobre o assunto da arenga; a seguir, são apresentados quatro versos com rimas do tipo $\mathrm{ABAB}$, que foram preservadas na tradução; na sequência, há o discurso de Safo a Erina propriamente dito; por fim, outros oito versos são apresentados, dessa vez com rimas do tipo AABB, também mantidas em português, e, ao final, apresenta-se um fechamento ao discurso, intitulado "efeito desta arenga", no qual o interlocutor reafirma a eficiência do discurso proferido, mencionando os êxitos posteriores das duas poetisas. Há, portanto, a voz de Safo, que se dirige à amiga Erina, e há a voz de um narrador que introduz o discurso. Em ambos os momentos, o uso do pronome vous é recorrente, não sendo utilizado o pronome em francês $t u$, empregado principalmente em contextos informais e familiares. Na tradução, contudo, optou-se por uma distinção entre essas duas vozes: o pronome "vós" para o narrador que introduz e encerra o argumento, o que dá um tom mais sério e solene, e o pronome "tu" para se referir a Erina, dando um tom menos formal, já que se trata de um diálogo (fictício) entre as duas poetisas. 


\begin{tabular}{|c|c|}
\hline $\begin{array}{c}\text { LES FEMMES ILLVSTRES, OU LES } \\
\text { HARANGVES HEROIQVES }\end{array}$ & $\begin{array}{c}\text { AS MULHERES ILUSTRES, OU AS } \\
\text { ARENGAS HEROICAS }\end{array}$ \\
\hline $\begin{array}{c}\text { SAPHO A ERINNE. VINGTIESME } \\
\text { HARANGVE. }\end{array}$ & SAFO A ERINA. VIGÉSIMA ARENGA. \\
\hline Argvment & Argumento \\
\hline $\begin{array}{l}\text { Vovs allez entendre parler cette Illufre } \\
\text { femme, dont tous les fiecles ont tant parlé : } \\
\text { que Platon mefme admiroit ; dont l'image a } \\
\text { efté grauée, comme celle d'une Deeffe, dans } \\
\text { toute la monnoye d'vn grand Peuple; dont } \\
\text { il nous refte encore vne efpece de Poëfie, } \\
\text { dont les vers font appellez Saphiques, à } \\
\text { caufe que ce fut elle, qui en inventa la } \\
\text { mefure; \& que deux grands Hommes de } \\
\text { l'Antiquité Grecque \& Romaine, ont } \\
\text { appellée la dixiefme Mufe. Ie luy fais } \\
\text { prendre l'occafion, d'exorter fon amie à } \\
\text { faire des vers comme elle, afin de faire voir } \\
\text { que les Dames en font capables: \& qu'elles } \\
\text { ont tort de négliger, vne fi agréable } \\
\text { occupation. C'eft l'Argument de cette } \\
\text { Harangue, que ie donne en particulier, à la } \\
\text { gloire de ce beau fexe; comme en general, } \\
\text { ie luy ay donné tout ce volume. }\end{array}$ & $\begin{array}{l}\text { Vós ouvireis falar aquela mulher ilustre de } \\
\text { quem tanto se falou ao longo dos séculos, } \\
\text { que foi admirada pelo próprio Platão; aquela } \\
\text { cuja imagem fora gravada, como a de uma } \\
\text { deusa, por toda a moeda de uma grande } \\
\text { nação; de quem nos resta ainda uma espécie } \\
\text { de poesia, cujos versos foram chamados } \\
\text { "sáficos", porque foi ela quem inventou a } \\
\text { medida, e a quem dois grandes homens da } \\
\text { antiguidade greco-romana chamaram "a } \\
\text { décima musa". Estou dando-lhe a } \\
\text { oportunidade para exortar sua amiga a } \\
\text { escrever versos assim como ela fazia, a fim } \\
\text { de mostrar que as mulheres também são } \\
\text { capazes disso, e que elas se enganam ao } \\
\text { negligenciar uma ocupação tão satisfatória. } \\
\text { Tal é o argumento desta arenga, a qual } \\
\text { ofereço em particular à glória desse belo } \\
\text { sexo, assim como de um modo geral este } \\
\text { volume lhe é inteiramente dedicado. }\end{array}$ \\
\hline $\begin{array}{l}\text { Viens voir en cette belle chofe, } \\
\text { L'estonnement de l'Vniuers: } \\
\text { Mais fouuiens-toy que cette Profe, } \\
\text { N'eft pas fi belle que Jes Vers. }\end{array}$ & $\begin{array}{l}\text { Contemplai essa coisa valiosa, } \\
\text { A maravilha dos Universos. } \\
\text { Mas não vos esqueçais de que essa prosa, } \\
\text { Não é tão valiosa quanto estes versos. }\end{array}$ \\
\hline SAPHO A ERINNE & SAFO A ERINA \\
\hline $\begin{array}{l}\text { Il faut Erinne, il faut que ie furmonte } \\
\text { auiourd'huy en voftre ame, cette deffiance } \\
\text { de vous-mefme, \& cette fauffe honte, qui } \\
\text { vous empefchent d'employer voftre efprit, } \\
\text { aux chofes dont il eft capable. Mais il faut } \\
\text { auparauant que de vous parler de voftre }\end{array}$ & $\begin{array}{l}\text { É preciso, Erina, é preciso, hoje, que eu te } \\
\text { ajude a superar essa descrença de si mesma } \\
\text { e essa falsa modéstia que te impede de usar } \\
\text { a mente para fazer tudo o que ela é capaz. } \\
\text { Mas antes, é preciso falar do teu mérito em } \\
\text { particular, mostrar o do nosso sexo em geral, }\end{array}$ \\
\hline
\end{tabular}


merite en particulier, que ie vous faffe voir celuy de noftre fexe en general : afin que par cette connoiffance, ie vous puiffe porter plus ayfémẽnt à ce que ie veux. Ceux qui difent que la Beauté, eft le partage des femmes ; \& que les beaux Arts, les belles lettres, \& toutes les fciences fublimes \& releuées, font de la dominatiõ des hommes, fans que nous y puiffions prétendre aucune part ; font efgallement efloignez, de la iuftice \& de la vérité. Si la chofe eftoit ainfi, toutes les femmes feroient nées auec de la beauté, \& tous les hommes avec vne forte difpofition à deuenir fçauants : autrement, la Nature feroit iniufte, en la difpenfation de fes Threfors. Cependant nous voyons tous les iours, que la laydeur fe troune dans noftre fexe, \& la ftupidité dans l'autre. Que s'il eftoit vray, que la Beauté fuft le feul aduantage, que nous euffions receu du Ciel, non feulement toutes les femmes feroient belles, mais ie crois encor, qu'elles le feroiẽt iufques à la mort; que le Temps refpecteroit en elles, ce qu'il deftruit à tous les momẽts ; \& que n'eftans enuoyées au monde, que pour y faire voir leur Beauté ; elles feroient belles, tant qu'elles feroient au monde. En effect, ce feroit vne eftrange deftinée, de furuiure vn fiecle, à la feule chofe, qui pourroit nous rendre recommandables : \& de ce grand nombre d'années, qui nous conduifent au Tombeau, n'en paffer que cinq ou fix auecques gloire.

Les chofes que la Nature femble n'auoir faites, que pour l'ornement de l'Vniuers; ne perdent prefque iamais la Beauté, qu'elles leur a vne fois donnée. L'or, les perles, \& les diamants, conferuent leur efclat auffi long-temps que leur eftre : \& le Phenix mefme à ce que l'on dit, meurt auecques fa beauté, pour reffufciter auec elle. Difons donc apres cela, que puis que nous ne de modo que, por meio deste conhecimento, eu possa te demonstrar mais facilmente o que quero dizer. Aqueles que dizem que a beleza é atributo das mulheres, e que as belas-artes, as belas-letras e todas as ciências sublimes e elevadas pertencem ao domínio dos homens, sem que tenhamos direito a nenhuma parte, estão igualmente distanciados da justiça e da verdade. Se a coisa fosse assim, todas as mulheres teriam nascido belas e todos os homens teriam nascido com uma forte disposição para se tornarem sábios; caso contrário, a natureza seria injusta na divisão dos tesouros. No entanto, vemos diariamente a fealdade em nosso sexo e a estupidez no outro. Se fosse verdade que tivéssemos tido a beleza como único dom recebido dos céus, não somente todas as mulheres seriam belas, mas penso, ainda, que o seriam até a morte, que o tempo pouparia nelas o que destrói a todo instante e que, tendo sido enviadas ao mundo simplesmente para exibir sua beleza, elas seriam belas pelo tempo que passassem no mundo. De fato, seria um destino estranho, sobreviver um século inteiro tendo apenas uma única coisa que poderia nos tornar louváveis, e, dessa longa soma de anos que nos conduz ao túmulo, ter apenas cinco ou seis de glória.

Essas coisas que a natureza parece ter feito somente para enfeitar o universo dificilmente perdem a beleza que alguma vez lhes foi dada. Ouro, pérolas e diamantes conservam o brilho por toda a existência, e até mesmo a fênix, pelo que dizem, morre com a beleza para depois ressuscitar com ela. Deduzimos, então, já que não vemos nem rosas, nem lírios, na tez da maior das 
voyons point de rofes ny de lys fur le teint des plus belles, que la rigueur de quelques hyuers ne fletriffe; que nous ne voyons point d'yeux, qui apres auoir efté plus efclatants que le Soleil, ne fe couurent de tenebres ; \& qui apres auoir faict cent Illuftres conqueftes, ne fe trounent en eftat de ne voir prefques plus que les conqueftes des autres ; difons dis-je, que puis que nous voyons que chaque inftant de la vie, nous dérobe malgré nous \& malgré nos foins, les plus belles chofes que nous ayons; que le temps emporte noftre ieuneffe; que ces filets d'or où tant de cours fe prennent, ne feront plus vn iour que des filets d'argent ; \& qu'enfin cét air de la Beauté, qui fe mefle fi agreablement, dans tous les traits d'vn beau vifage; \& où l'on voit paroiftre vn rayon de la Diuinité ; n'eft pas affez fort, pour vaincre les maladies, le temps, \& la vieilleffe ; Concluons dis-je, qu'il faut de neceffité, que nous ayons d'autres aduantages que celuy-la.

Et pour en parler raifonnablement, la Beauté eft en noftre fexe, ce que la valeur eft en celuy des hommes : mais comme cette qualité ne les empefche pas, d'aymer l'eftude des belles lettres ; cét aduantage auffi, ne nous empefche point, de les apprendre \& de les f̧̧auoir. Que s'il y a quelque difference, entre les hommes \& les femmes, ce doit eftre feulement, pour les chofes de la guerre : c'eft à la Beauté de mon fexe à conquefter les cours ; \& à la valeur, \& à la force des hommes, à conquefter des Royaumes. L'intention de la Nature, paroift fi claire en cette rencontre, qu'on ne s'y peut oppofer : ie confents donc, que nous laiffiõs prendre des Villes, donner des batailles, \& conduire des armées, à ceux qui font nez pour cela : mais pour les chofes qui n'ont befoin, que de l'imagination, de la beldades, que o rigor de alguns invernos não murche, e já que não vemos olhos que não se ofuscam depois de terem sido mais radiantes que o sol, e os quais, depois de terem feito uma centena de conquistas ilustres ficam reduzidos a meros observadores das conquistas alheias, deduzimos, digo eu, já que vemos que cada instante da vida nos tira, contra nossa vontade e apesar de todos os esforços, aquilo que temos de mais caro, já que o tempo leva embora nossa mocidade, e já que as redes de ouro que apanharam tantos corações um dia se transformam em redes de prata, e finalmente, já que este ar de beleza que se mescla agradavelmente em todos os traços de um belo rosto, e onde vemos aparecer um vislumbre de divindade, não é forte o bastante para vencer as doenças, o tempo e a velhice, concluímos, digo eu, que devemos possuir outras qualidades além dessa.

E, para dizer de forma sensata, a beleza está em nosso sexo assim como a bravura está no dos homens, mas da mesma forma que esse traço não os impede de apreciar o estudo das belas-letras, nossa beleza também não nos impede de conhecê-las. Se houver alguma diferença entre homens e mulheres, existe apenas nos assuntos da guerra: a beleza do meu sexo conquista os corações, enquanto a bravura e a força dos homens conquistam os reinos. A intenção da natureza parece ser tão clara nesse caso que não se pode negá-la: consinto, então, que deixemos o tomar cidades, promover batalhas e liderar exércitos àqueles que nasceram para isso; mas para as coisas que exigem imaginação, argúcia da mente, memória e juízo, dessas não tolero que sejamos desapropriadas. 


\begin{tabular}{|c|c|}
\hline $\begin{array}{l}\text { viuacité de l'efprit, de la memoire, \& du } \\
\text { iugement ; ie ne fçaurois fouffrir que l'on } \\
\text { nous en priue. }\end{array}$ & \\
\hline $\begin{array}{l}\text { Les hommes, qui comme vous fçauez, font } \\
\text { prefques tous nos efclaues, ou nos ennemis; } \\
\text { quand mefme les chaifnes que nous leur } \\
\text { faifons porter leur femblent trop pefantes, } \\
\text { ou que les ayants brifées, ils font les plus } \\
\text { irritez contre nous ; ne nous difputent } \\
\text { pourtant point, n'y la Beauté de } \\
\text { l'imagination; n'y la viuacité de l'efprit ; } \\
\text { n'y la force de la memoire; mais pour le } \\
\text { iugement, quelques-vns ont l'iniuftice de } \\
\text { foutenir, qu'ils en ont plus que nous. Ie } \\
\text { penfe toutesfois, que la moderation, \& la } \\
\text { modeftie de noftre fexe, font affez voir que } \\
\text { nous n'en manquons point : \& puis, s'il eft } \\
\text { vray que nous poffedions ces premiers } \\
\text { aduantages au founerain degré ; il eft } \\
\text { prefques impoffible, que nous ne poffedions } \\
\text { pas l'autre. Car fi noftre imagination, nous } \\
\text { monftre les chofes comme elles font ; fi } \\
\text { noftre efprit les connoit parfaitement; \& fi } \\
\text { noftre memoire nous fert comme il faut; le } \\
\text { moyen que noftre iugement puiffe errer? } \\
\text { L'imagination quand elle eft viue, eft vn } \\
\text { miroir fi fidelle ; l'efprit quand il eft } \\
\text { illuminé, penetre fi profondement les chofes } \\
\text {; \& la memoire quand elle eft heureufe \& } \\
\text { cultiuée, inftruit fi puiffamment par } \\
\text { l'exemple ; qu'il eft impoffible, que le } \\
\text { iugement ne fe forme pas. }\end{array}$ & $\begin{array}{l}\text { Os homens - como tu sabes, são quase } \\
\text { todos ou nossos escravos, ou nossos } \\
\text { inimigos, e mesmo quando as correntes que } \\
\text { nós os obrigamos a carregar parecem muito } \\
\text { pesadas, ou quando são quebradas, tornam- } \\
\text { se os mais bravos com a gente - não nos } \\
\text { disputam nem a beleza da imaginação, nem } \\
\text { a argúcia da mente, nem a força da } \\
\text { memória. Mas com relação ao juízo, alguns } \\
\text { afirmam injustamente que o possuem mais } \\
\text { do que nós. Penso, todavia, que a moderação } \\
\text { e a modéstia do nosso sexo são suficientes } \\
\text { para demonstrar que não nos falta nada } \\
\text { nessa área; e, além disso, se for verdade que } \\
\text { possuamos no mais soberano grau aquelas } \\
\text { primeiras qualidades, então seria } \\
\text { praticamente impossível que não possuamos } \\
\text { a última. Porque se a nossa imaginação nos } \\
\text { mostra as coisas tais como são, se a nossa } \\
\text { mente nos deixa conhecê-las perfeitamente, } \\
\text { e se a nossa memória nos serve como deve } \\
\text { servir, como seria possível nosso juízo } \\
\text { falhar? A imaginação, quando é vivaz, é um } \\
\text { espelho tão fiel; a razão, quando é } \\
\text { iluminada, penetra tão profundamente nas } \\
\text { coisas; e a memória, quando é hábil e } \\
\text { cultivada, instrui tão poderosamente pelo } \\
\text { exemplo que é impossível não desenvolver o } \\
\text { juízo. }\end{array}$ \\
\hline $\begin{array}{l}\text { Croyez-moy Erinne, quand la mer eft calme, } \\
\text { il eft difficile de faire naufrage; le plus } \\
\text { maunais Pilote peut entrer au port; \& il } \\
\text { n'eft point d'efcueils, que l'on ne puiffe } \\
\text { efuiter quand on les voit, \& que les vagues } \\
\text { ne font point efmeuës. Pour moy ie vous } \\
\text { aduouë que ie ne comprends pas, que ceux } \\
\text { qui nous laiffent l'imagination, l'efprit, \& la } \\
\text { memoire en partage; puiffent fe vanter, } \\
\text { d'auoir plus de iugement que nous. Car le }\end{array}$ & $\begin{array}{l}\text { Confia em mim, Erina, quando o mar está } \\
\text { calmo, é difícil naufragar; o pior piloto é } \\
\text { capaz de entrar no porto, e não há rochedos } \\
\text { que não possam ser evitados quando os } \\
\text { vemos e quando as ondas não estão agitadas. } \\
\text { Quanto a mim, confesso que não entendo } \\
\text { como aqueles que nos deixam ter a } \\
\text { imaginação, a inteligência e a memória } \\
\text { possam se vangloriar de ter mais juízo do } \\
\text { que nós, pois se a imaginação não lhes }\end{array}$ \\
\hline
\end{tabular}


moyen de penfer, que leur imagination, ne leur montrant pas les chofes comme elles font; que leur efprit, ne les connoiffant pas parfaitement ; \& que leur memoire, ne leur eft pas fidelle; le moyen dis-je, de penfer, que fur des raports fi faux, leur iugement puiffe agir equitablement? non Erinne, cela n'eft pas poffible: \& pour eftre plus raifonnables que quelques-vns d'entr'eux; difons, que parmy eux \& parmy nous, il y a des perfonnes qui ont tout enfemble, de l'imagination, de l'esprit, de la memoire, \& du iugement.

Ce n'eft pas que fi ie le voulois, ie ne puffe faire voir, par vne induction forte \& puifsante; que noftre fexe pourroit fe vanter, d'eftre plus riche des Threfors de l'efprit que celuy des hommes. Car confiderez Erinne, cét ordre prefques Vniuerfel, que l'on voit entre tous les animaux, qui viuent dans les bois \& dans les cauernes: vous verrez, que ceux qui font nez auec de la force \& du cour, font bien founent peu adroits, \& peu intelligents: \& que les foibles pour l'ordinaire, ont vn inftinct plus puiffant, \& font plus près de la raifon ; que ceux à qui la Nature, a donné d'autres aduantages. Vous iugez bien que, felon cét ordre, la Nature ayant donné plus de force \& plus de courage aux hommes qu'aux femmes ; elle doit auffi nous auoir donné, \& plus d'efprit, \& plus de iugement: Mais encore vne fois Erinne, accordons leur qu'ils en ont autãt que nous ; pourueu qu'ils demeurent auffi d'accord, que nous en auõs autant qu'eux.

Vous me direz peut-eftre, que quand $d u$ confentement de tous les hõmes, i'auray obtenu cette déclaration; ie ne pourray pas encore vous perfuader, que la connoiffance de belles lettres, foit bienfeante à vne femme: puis que par vn vage que les mostra as coisas como são, se a mente não os deixa discerni-las muito bem, e se a memória não lhes é tão eficaz, se os meios de pensar têm fundamentos tão imprecisos, como poderia o juízo deles agir de forma justa? Não, Erina, isso não seria possível, e para ser mais sensata que alguns desses, concordemos que entre eles e entre nós há pessoas que têm ao mesmo tempo imaginação, inteligência, memória e juízo.

Não que eu não pudesse mostrar, se assim o quisesse, usando um firme e rigoroso raciocínio, que o nosso sexo pode se vangloriar de ser mais rico do que o dos homens quando se trata de tesouros da mente. Considera, Erina, essa lei quase universal que vemos entre todos os animais que habitam as florestas e as cavernas: verás que aqueles que nascem com força $\mathrm{e}$ coragem são frequentemente pouco hábeis e pouco inteligentes, e que os fracos normalmente possuem um instinto mais aguçado e estão mais próximos da razão do que aqueles para os quais a natureza deu outras qualidades. Tu podes muito bem concluir, seguindo tal princípio, uma vez que a natureza deu mais força e mais coragem aos homens do que às mulheres, que ela também deve ter-nos dado mais inteligência e mais juízo. Mas, novamente, Erina, concedamos que eles tenham o mesmo que nós, contanto que eles concordem que tenhamos o mesmo que eles. Tu me dirás, talvez, que mesmo conseguindo essa declaração de todos os homens, eu ainda assim não poderia te assegurar que o conhecimento das belasletras seja apropriado para uma mulher, porque, devido a convenções estabelecidas 


\begin{tabular}{|c|c|}
\hline $\begin{array}{l}\text { hommes ont eftably, de crainte peut-eftre } \\
\text { d'eftre furmontez par nous, l'eftude nous eft } \\
\text { auffi defenduë que la guerre. Faire des Vers, } \\
\text { eft mefme chofe que donner des batailles, fi } \\
\text { nous les en voulons croire: \& pour tout } \\
\text { dire, il femble que l'on ne nous permet, que } \\
\text { ce que l'on nous deuroit pluftoft defendre. }\end{array}$ & $\begin{array}{l}\text { por homens, talvez por medo de serem } \\
\text { superados por nós, o estudo nos é tão } \\
\text { proibido quanto a guerra. Escrever versos é } \\
\text { o mesmo que travar guerras, se quisermos } \\
\text { acreditar nelas, e para dizer a verdade, } \\
\text { parece que só nos permitem aquilo que } \\
\text { deveriam antes nos proibir. }\end{array}$ \\
\hline $\begin{array}{l}\text { Quoy Erinne, nous aurons l'imagination } \\
\text { belle; l'efprit clair-voyant; la memoire } \\
\text { heureufe ; le iugement folide; \& nous } \\
\text { n'employerons toutes ces chofes, qu'à frifer } \\
\text { nos cheueux, \& qu'à chercher les } \\
\text { ornements, qui peuuent adioufter quelque } \\
\text { chofe à noftre Beauté! non Erinne, ce feroit } \\
\text { abufer inutilement, des faueurs que nous } \\
\text { auons receuës du Ciel. Celles qui font nées } \\
\text { auec des yeux à faire des conqueftes, n'ont } \\
\text { que faire de ioindre l'artifice, aux graces de } \\
\text { la Nature: \& ce feroit donner vn indigne } \\
\text { employ à l'efprit, que de ne le faire agir } \\
\text { toute noftre vie, qu'à de femblables } \\
\text { occupations. }\end{array}$ & $\begin{array}{l}\text { Por que, Erina, teríamos uma boa } \\
\text { imaginação, uma mente perceptiva, uma } \\
\text { memória lúcida e um juízo sólido apenas } \\
\text { para enrolar nossos cabelos e procurar } \\
\text { enfeites que pudessem acrescentar algo na } \\
\text { nossa beleza? Não, Erina, isso seria } \\
\text { desperdiçar as dádivas que recebemos dos } \\
\text { céus. Aquelas que nascem com olhos feitos } \\
\text { para conquistar não fariam nada senão } \\
\text { acrescentar artifícios às graças da natureza } \\
\text { — e passar toda a vida com tarefas } \\
\text { semelhantes seria dar uma ocupação indigna } \\
\text { à mente. }\end{array}$ \\
\hline $\begin{array}{l}\text { On pourroit mefme dire, que fi les chofes } \\
\text { eftoient ordonnées comme il faut, l'efttude } \\
\text { des belles lettres, deuroit pluftoft eftre } \\
\text { permife aux femmes qu'aux hommes : car } \\
\text { comme ils ont la conduite de l'Vniuers; que } \\
\text { les vns font Roys; les autres Gounerneurs } \\
\text { de Prouinces; quelques-vns Sacrificateurs; } \\
\text { les autres Magiftrats; \& tous en General, } \\
\text { Maiftres de leurs familles : \& par } \\
\text { confequent occupez, ou aux affaires du } \\
\text { Public, ou aux leurs en particulier; ils ont } \\
\text { fans doute peu de temps à donner, à cette } \\
\text { forte d'eftude. Il faut qu'ils le dérobent à } \\
\text { leurs fuiets, à leurs amis, ou à eux-mefmes: } \\
\text { mais pour nous, noftre loifir \& noftre } \\
\text { retraicte, nous en donnent toute la facilité, } \\
\text { que nous pourrions fouhaitter. Nous ne } \\
\text { dérobons rien au Public ny à nous mefmes: } \\
\text { au contraire, nous nous enrichiffons, fans } \\
\text { apauurir les autres, nous illuftrons noftre }\end{array}$ & $\begin{array}{l}\text { Poder-se-ia dizer, também, que se as coisas } \\
\text { estivessem ordenadas como devem ser, o } \\
\text { estudo das belas-letras deveria ser permitido } \\
\text { mais às mulheres do que aos homens, pois } \\
\text { como eles estão no comando do universo - } \\
\text { alguns são reis, outros governadores de } \\
\text { províncias, alguns são sacerdotes, outros } \\
\text { magistrados, e todos, em geral, são chefes } \\
\text { de suas famílias e, consequentemente, } \\
\text { ocupados com assuntos públicos ou } \\
\text { negócios particulares -, certamente } \\
\text { possuem pouco tempo para se dedicar a esse } \\
\text { tipo de estudo. Eles precisam roubar tempo } \\
\text { dos seus assuntos, dos seus amigos ou deles } \\
\text { mesmos. Mas, para nós, nosso ócio e nosso } \\
\text { retiro nos dão toda a oportunidade que } \\
\text { poderíamos desejar. Não roubamos tempo } \\
\text { do que fazemos na esfera pública ou de nós } \\
\text { mesmas; pelo contrário, enriquecemo-nos } \\
\text { sem precisar empobrecer outros; trazemos }\end{array}$ \\
\hline
\end{tabular}


Patrie, en nous rendans Illuftres; \& fans faire tort à perfonne, nous aquerons beaucoup de gloire. Il eft bie iufte ce me Semble, puis que nous laiffons la domination aux hommes, qu'ils nous laiffent du moins la liberté, de connoiftre toutes les chofes, dont noftre efprit eft capable: Le defir du bien, ne nous doit point eftre defendu: \& par confequent, ce n'eft pas vn crime de le pratiquer.

Les Dieux n'ont riẽ faict d'inutile en toute la Nature: chaque chofe fuit l'ordre, qui luy a efté donné: le Soleil efclaire \& efchauffe l'Vniuers: la Terre nous donne tous les ans des fleurs \& des fruicts : la mer nous donne toutes fes richeffes: les riuieres arroufent nos prairies: les bois nous preftent leurs ombrages : \& toutes chofes enfin, feruent à la focieté Publique. Cela eftant ainfi, pourquoy veut-on que nous foyons les feules rebelles \& mefconnoiffantes enuers les Dieux? pourquoy veut on dis-je, que noftre Efprit foit ou indignement employé, ou eternellement inutile? qu'elle bien-feance peut-il y auoir, à mefprifer ce qui eft honnefte? \& quelle raifon peut tomber d'accord, que ce qui eft infiniment loüable de foy, deuienne maunais \& condamnable dés qu'il eft en nous?

Ceux qui ont des efclaues, les font inftruire pour leur commodité : \& ceux que la Nature ou l'vsage, nous ont donnez pour Maiftres, veulent que nous efteignions en noftre ame, toutes les lumieres que le Ciel y a mifes : \& que nous viuions, dans les plus efpaiffes tenebres de l'ignorance. Si c'eft pour obtenir plus ayfément noftre admiration, ils n'arriuent pas à leur fin: puis que nous n'admirons point ce que nous ne connoiffons pas. Que fi c'eft auffi, pour nous rendre plus affuietties, ce fentiment n'eft pas genereux: \& s'il eft vray, qu'ils ayent honra à nossa nação ao trazer honra a nós mesmas; e sem fazer mal a ninguém, alcançamos grande glória. Parece-me justo, já que deixamos os homens dominarem tudo, que eles nos deixem ao menos a liberdade de conhecer todas as coisas das quais nossa mente é capaz. O desejo de fazer bem as coisas não nos deve mais ser proibido e, por consequência, deixa de ser crime de praticá-lo.

Os deuses não criaram nada sem utilidade em toda a natureza; cada coisa segue um plano estabelecido: o sol ilumina e aquece o universo; a terra nos dá flores e frutas em abundância; o mar nos oferece todas as suas riquezas; os rios irrigam nossos prados; as florestas nos cedem suas sombras; e, de fato, tudo isso é útil para a sociedade. Sendo assim, por que querem que sejamos as únicas rebeldes e ingratas com os deuses? Por que querem, então, pergunto eu, que nossa mente seja usada de forma indigna e sempre sem utilidade? Que dignidade pode haver em querer desprezar o que é honesto? E por qual razão devemos concordar que o que é infinitamente louvável em alguém se torna logo condenável se estiver em nós?

Aqueles que têm escravos os educam para sua própria conveniência, mas aqueles que a natureza ou o costume nos deram como mestres querem que apaguemos em nossas almas todas as luzes que os céus ali colocaram e que vivamos nas mais profundas trevas da ignorância. Se é para conseguir mais facilmente nossa admiração, eles não atingiram o objetivo, pois não podemos admirar aquilo que não conhecemos; se é para nos tornar mais subservientes, isso não merece estima; e se é verdade que eles têm algum poder sobre 
quelque Empire fur nous, c'eft rendre leur domination peu glorieufe, que de regner fur des ftupides \& fur des ignorantes.

Vous me direz peut-eftre, que tous les hommes ne nous font pas fi rigoureux : \& que quelques-vns confentent, que les femmes employent leur efprit, à la connoiffance des belles lettres: pourueu qu'elles ne fe meflent pas, de vouloir elles mefmes compofer des ouurages. Mais que ceux qui font de cette opinion fe founiennent, que fi Mercure \& Apollon font de leur fexe, Minerue \& les Mufes font du noftre. J'aduouë neantmoins, qu'ayant autant receu du Ciel que nous auons, nous ne deuons pas nous engager legerement, à vne femblable chofe. La honte par exemple, n'eft pas à faire des Vers; mais à en faire mal : \& fi les miens n'auaient eu le bon-heur de plaire, ie n'en aurois iamais monftré deux fois. Cette honte ne nous eft pas toutesfois particuliere: \& quiconque faict mal vne chofe, qu'il entreprend volontairement; merite fans doute d'en eftre blafmé, de quelque fexe qu'il puiffe eftre. Vn maunais Orateur, vn maunais Philofophe, \& vn maunais Poëte, n'acquierent guere plus de gloire, qu'vne femme qui s'acquiteroit de maunaife grace de toutes ces chofes : \& de quelque fexe que l'on foit, on merite reprehenfion quand on faict mal; \& beaucoup d'eftime quand on faict bien. Mais pour donner quelque chose à l'vfage, \& à la deprauation du fiecle; laiffez Erinne, toutes ces fciences efpineufes, à ceux qui n'ayment à chercher la gloire, que par des fentiers difficiles.

Ie ne veux pas vous conduire, en des lieux où vous ne voyez rien d'agreable: Ie ne veux pas que vous paffiez toute voftre vie, dans les importunes recherches, de ces fecrets qu'on ne trouue point: Ie ne veux nós, não há glória nenhuma em dominar apenas estúpidas e ignorantes.

Tu me dirás, talvez, que nem todos os homens são tão severos e que alguns até deixam as mulheres usarem a mente para estudar as belas-letras, desde que não venham querer produzir elas mesmas essas obras. Mas esses que defendem tal opinião devem recordar que se Mercúrio e Apolo são do seu sexo, Minerva e as Musas são do nosso $^{6}$. No entanto, devo confessar que, tendo recebido tanto dos céus, não devemos nos engajar em tal coisa de forma amena. A vergonha, por exemplo, não é escrever versos, mas escrevê-los mal, e se os meus não tivessem tido a boa sorte de agradar, nunca os teria exibido duas vezes. Tal vergonha não é exclusividade nossa; quem não faz direito algo produzido espontaneamente, sem dúvida, merece ser culpado, independentemente do sexo. Um mal orador, um mal filósofo e um mal poeta dificilmente conseguem mais glória do que uma mulher que se empenha em tudo isso a contragosto. E não importa o sexo, deve ser reprovado aquilo que é feito mal e deve ser apreciado aquilo que é feito bem. Mas porque o costume e a depravação desta época determinam, Erina, concedamos todas essas ciências espinhosas para aqueles que preferem buscar a glória por caminhos tortuosos.

Não desejo te conduzir a lugares onde tu só verás coisas desagradáveis; não quero que tu passes a vida nessa busca cansativa por segredos sem solução; não desejo te ver usar a inteligência de modo inútil para descobrir 
pas que vous employez tout voftre efprit inutilement, à connoiftre en quel lieu les vents font leur retraite, apres auoir fait faire des naufrages: \& ie ne veux pas enfin, que vous confumiez le refte de vous iours, à Philofopher indifferemment fur toutes chofes. I'ayme voftre repos, voftre gloire, \& voftre Beauté tout enfemble: ie ne veux point pour vous de ces fortes d'eftude, qui rendent le teint iaune; les yeux enfoncez; le vifage haue; qui rendent l'humeur fombre $\&$ inquiete. Ie ne veux point que vous fuyez la focieté ny la lumiere: mais ie veux feulement, que vous me fuiuiez aux bords $d u$ Permeffe. C'eft-là Erinne, que ie vous veux conduire : c'eft-là que vous me furpafferez, auffi-toft que vous y ferez arrinée : c'eft là que vous acquerrez vne Beauté, que le Temps, les années, les faisons, la vieilleffe, \& la mort mefme, ne pourront vous dérober: \& c'est là enfin, que vous connoiftrez parfaitement, que noftre fexe eft capable, de tout ce qu'il veut entreprendre.

Vous me direz peut-eftre, qu'en voulant vous porter à la Poëfie, ie ne vous tiens pas ma parole: puis que dans les defcriptions que l'on fait de ceux qui font des vers, il femble que la Beauté ne peut compatir, avec les grimaces que l'on leur faict faire. Mais fçachez Erinne, que cela n'eft qu'vne inuention des hommes : qui ont voulu faire entendre, que comme nous voyons ceux qui rendent les Oracles, eftre troublez par la prefence du Dieu qui les faict parler; de mefme auffi, la Poëfie eftant toute diuine, trouble ceux qui la pratiquent. Mais quand cela feroit ainfi, vos yeux n'en feroient pas moins clairs : car comme lors que l'oracle eft rendu, le Preftre retrouue fa premiere tranquillité ; vous n'aurez pas auffi pluftoft quité la plume, que vous retrounerez vos premieres graces. Et puis, ie ne penfe pas para onde os ventos vão depois de terem causado naufrágios; e, por fim, não quero que tu gastes o resto dos teus dias filosofando com indiferença sobre todas as coisas. Eu me importo com a tua tranquilidade, glória e beleza, todas juntas: não quero para ti esses estudos que deixam a pele amarelada, os olhos com olheiras, o rosto empalidecido, rugas na testa e o humor sombrio e inquieto. Não quero que tu fujas da sociedade ou da luz do dia. Quero antes que tu me sigas até as bordas do Parnaso ${ }^{7}$. É para esse lugar, Erina, que eu gostaria de te guiar; é nesse lugar que tu deves me superar desde o momento da tua chegada; é nesse lugar que tu atingirás uma beleza que nem o tempo, nem os anos, nem as estações, nem a velhice, nem a própria morte poderão te roubar; é nesse lugar, finalmente, que tu compreenderás plenamente que o nosso sexo é capaz de tudo aquilo que almejamos realizar.

Tu me dirás talvez que, ao querer te conduzir à poesia, eu falto com minha palavra, já que a beleza parece ser incompatível com os semblantes carrancudos que são atribuídos àqueles que escrevem versos. Mas saiba, Erina, que isso não passa de uma invenção dos homens que quiseram que acreditássemos nisso; assim como vemos aqueles que leem os oráculos serem perturbados pela presença do deus que os faz falar, tão divina poesia irá igualmente incomodar aqueles que a praticam. Mas mesmo que isso acontecesse, teus olhos não ficariam menos reluzentes, pois assim como o sacerdote reencontra a sublime paz após o oráculo ter se pronunciado, tu também voltarás ao estado de graça de antes, assim que tiveres deixado a pluma. E, além disso, não penso que tu 
que vous rempliffiez iamais voftre efprit, de $f i$ funeftes images, qu'il en puiffe reiallir, quelque chofe de funefte dans vos yeux.

Vous ferez Maiftreffe abfoluë, des fuiets que vous voudrez traicter : \& de tant de beautez qui font en la Nature, vous pourrez choifir celle, qui touchera le plus voftre inclination. La defcription d'vn bois, ou d'vne fontaine; les pleintes d'vn Amant \& d'vne Maiftrefse; ou l'Eloge de quelque vertu; vous donneront d'affez amples fuiets, de faire paroiftre les Talents, que le Ciel a mis en voftre perfonne. Vous eftes née auec de fi glorieux aduantages, que vous feriez ingrate enuers ceux qui vous les ont donnez, $f i$ vous n'en fçauiez pas bien ver.

Vous me demanderez peut-eftre, s'il n'eft pas affez glorieux à vne belle femme, que tous les beaux efprits de fon temps, faffent des vers à fa loüange, fans qu'elle fe mefle, de faire elle-mefme fon portraict? Vous me demanderez dis-je, fi fa gloire n'eft pas mieux eftablie de cette façon que de l'autre? mais i'ay à vous refpondre, que quelques Eloges que l'on vous puiffe donner, il vous feroit plus glorieux, d'auoir faict des vers pour tous les Illuftres de voftre fiecle, fi vous les faifiez bien; qu'il ne vous le feroit, qu'ils en euffent tous faict pour vous. Croyez-moy Erinne, il vaut mieux donner l'immortalité aux autres, que de la receuoir d'autruy: \& trouner fa propre gloire chez foy, que de l'attendre d'ailleurs. Les portraits que l'on feroit de vous de cette forte, ne pafferoient peut-eftre vn iour chez la Pofterité, que pour des tableaux faicts à plaifir. On admireroit plus l'imagination des Poëtes, que voftre beauté; \& les copies enfin, pafferoient pour Originaux. Mais $f i$ de voftre propre main, vous laiffez quelques marques de ce que vous eftes, vous viurez toufiours auec honneur, en la memoire de chegarias a ponto de preencher a cabeça com imagens tão atrozes de modo a transparecê-las nos teus olhos.

Tu serás a senhora absoluta dos assuntos que tu fores tratar, e das tantas belezas que a Natureza ostenta, tu poderás escolher aquela que melhor te apraz. A descrição de uma floresta ou de uma fonte, as lamúrias de um enamorado ou de sua amante, ou a exaltação de alguma virtude, tudo isso te proverá temas suficientemente diversos para que possas demonstrar os talentos com os quais os céus te agraciaram. Tu nasceste com qualidades tão gloriosas que seria uma imensa ingratidão da tua parte não fazer bom uso delas.

Talvez tu me perguntes se já não há bastante glória para uma bela mulher ser exaltada por todos os grandes poetas do seu tempo, sem ela precisar fazer seu próprio retrato, tu me perguntarás, eu sei, se a glória não estaria mais bem estabelecida dessa forma. Mas basta te responder que, por mais elogios que te possam dar, seria mais glorioso escrever versos para as pessoas ilustres do teu século, se tu os fizeres bem, do que se fossem eles que os tivessem escritos para ti. Acredita em mim, Erina, mais vale dar a imortalidade aos outros do que recebê-la dos outros, mais vale encontrar a glória consigo do que esperar que ela venha de fora. Esses retratos que os outros fazem, correm o risco de ficar para a posteridade apenas como quadros feitos por prazer. A imaginação dos poetas acaba sendo mais admirada do que a tua beleza, e as cópias, eventualmente, são tomadas por originais. Mas se deixares marcas de quem tu és com a própria mão, então viverás para sempre honrada na memória de todos. Aqueles que da tua época formularem elogios a tua pessoa parecerão sensatos e aqueles que não o fizerem 
tous les hommes; ceux de voftre fiecle qui vous auront loüée, pafferont lors pour veritables ; \& ceux qui ne l'auront pas faict, pour ftupides ou pour enuieux.

Ie ne pretends pas toutesfois, que vous faffiez voftre portraict; que vous parliez de voftre Beauté ; de voftre vertu ; \& de toutes les rares qualitez qui font en vous : Non, ie ne veux pas impofer, vne fi dure chofe à voftre modeftie. La Poëfie a bien d'autres priuileges: vous n'auez que faire de parler de vous, pour vous faire connoiftre à la Pofterité : vous n'auez qu'à parler de bonne grace, \& l'on vous connoiftra affez. Oüy, Erinne, quãd vous n'employeriez voftre plume, qu'à blafmer les vices de voftre fiecle, on ne laifferoit pas de vous loüer.

Confiderez donc encore vne fois ie vous en coniure ; combien foible \& peu durable, eft la reputation qui fe fonde fur la Beauté. De tout ce nombre infiny de belles femmes, qui ont fans doute vefcu dans les fiecles qui ont precedé le noftre, à peine auons nous oüy parler de deux ou trois feulement : \& dans ces mefmes fiecles, nous voyons la gloire de plufieurs hommes, folidement eftablie, par les efcrits qu'ils nous ont laiffez. Faites Erinne, que le Temps, la vieilleffe, \& la mort, ne vous dérobent que des rofes; \& qu'ils n'emportent pas toute voftre Beauté. Triomphez de ces ennemis de toutes les belles chofes: mettez-vous en eftat de foûtenir par voftre exemple, la gloire de noftre fexe: faites aduoüer à nos communs ennemis, qu'il nous eft auffi facile de les vaincre, par la force de noftre efprit, que par la Beauté de nos yeux: faites paroiftre voftre ingement, par le mefpris des fottifes, que le vulgaire dira, de voftre refolution: faites voir à toute la Terre, de fi beaux tableaux de voftre imagination; de fi nobles efforts de voftre efprit; de fi beaux effects de parecerão estúpidos ou invejosos.

No entanto, não estou exigindo que tu faças teu próprio retrato, que tu fales da tua beleza, da tua virtude, e de todas as tuas raras qualidades. Não, impor uma tarefa tão árdua para a tua modéstia não é o que desejo. A poesia oferece tantas possibilidades: basta que tu fales de ti para que te conheçam na posterioridade; basta falar com elegância, que serás muito bem conhecida. Sim, Erina, basta usar tua pluma para condenar os vícios da tua época para que as pessoas não deixem nunca de te exaltar.

Então, perceba mais uma vez, eu te peço, quão fraca e transitória é a fama fundada na beleza. Do número infinito de mulheres bonitas que, sem dúvida, viveram em todos os séculos que precederam o nosso, ouvimos falar apenas de duas ou três, mas nesses mesmos séculos vemos a glória de vários homens solidamente estabelecida por meio dos escritos que eles nos deixaram. Erina, permita que o tempo, a velhice e a morte te roubem apenas as rosas, mas não deixe que levem toda a beleza. Triunfa sobre esses inimigos em tudo o que há de mais belo; coloca-te em posição de defender, pelo teu próprio exemplo, a glória do nosso sexo; mostra aos nossos inimigos de sempre que é tão fácil vencê-los com a força da nossa inteligência, assim como através da beleza dos nossos olhos; mostra, com teu juízo, repúdio por essas injúrias, que o mais comum dos homens reconhecerá tua a determinação; mostra para o mundo inteiro, com os belos quadros da tua imaginação, com os notáveis esforços da tua mente, com a admirável eficiência da tua memória, e 


\begin{tabular}{|c|c|}
\hline $\begin{array}{l}\text { voftre memoire; \& de fi belles marques de } \\
\text { voftre iugement; que vous feule ayez } \\
\text { l'aduantage, d'auoir reftably la gloire de } \\
\text { toutes les femmes. Ne mefprisez donc pas ce } \\
\text { que ie vous dis : car fi par vne fauffe honte, } \\
\text { vous ne vous refoluez point à me fuiure; \& } \\
\text { que vous faffiez confifter, toute voftre gloire } \\
\text { en voftre Beauté; vous pleurerez de voftre } \\
\text { viuant, la perte de cette Beauté. L'on } \\
\text { parlera de vous, comme fi vous auiez efté } \\
\text { d'vn autre fiecle: \& vous trounerez lors, } \\
\text { que i'auray eu raifon de vous dire } \\
\text { auiourd'huy, ce que ie penfe auoir dit, } \\
\text { autrefois, dans quelques vns de mes Vers, }\end{array}$ & $\begin{array}{l}\text { com as provas sublimes do teu juízo, que tu } \\
\text { tens, por si só, o poder de reestabelecer a } \\
\text { glória de todas as mulheres. Não despreza o } \\
\text { que te digo, pois, se por uma falsa modéstia } \\
\text { tu decidires não seguir os meus conselhos e } \\
\text { concentrar toda a glória na tua beleza, irás } \\
\text { lamentar ainda em vida a perda dessa } \\
\text { mesma beleza. Falarão de ti como se tu } \\
\text { tivesses pertencido a outro século, e tu } \\
\text { perceberás, então, que eu tinha razão em te } \\
\text { dizer hoje o que penso ter dito outrora em } \\
\text { alguns destes meus versos. }\end{array}$ \\
\hline $\begin{array}{l}\text { Les lys, les oeillets, les Rofes, } \\
\text { Et toutes ces belles chofes, } \\
\text { Dont vostre vifage est peint ; } \\
\text { L'efclat des yeux \& du teint ; } \\
\text { Tout perdra forme \& matiere ; } \\
\text { Et vous mourrez toute entiere, } \\
\text { Si pour vaincre la Parque, \& la fatalité, } \\
\text { Vous n'allez par l'eftude, à l'immortalité. }\end{array}$ & $\begin{array}{l}\text { Os lírios, os cravos, as rosas, } \\
\text { E todas essas coisas primorosas, } \\
\text { Que à tua face dão cor; } \\
\text { Rosto e corpo cheios de fulgor; } \\
\text { Acabarão como um maltrapilho; } \\
\text { E tu inteira ficarás sem brilho, } \\
\text { Se, para vencer a parca e a fatalidade } \\
\text { Tu não chegares, pela instrução, à } \\
\text { [imortalidade. }\end{array}$ \\
\hline $\begin{array}{l}\text { L'on ne peut pas dire, que cette harangue } \\
\text { n'eut point d'effect, fi l'on prend les chofes } \\
\text { au pied de la lettre : car il paroit bien, que } \\
\text { celle à qui elle s'adreffoit; fe laiffa porter } \\
\text { où l'on voulut, puis qu'vne Epigramme } \\
\text { Grecque nous a dit; qu'autant que Sapho } \\
\text { furpaffoit Erinne en Poëfie Lyrique; autant } \\
\text { Erinne furpaffait Sapho, en vers } \\
\text { Hexametres. Que fi l'on s'efloigne du fens } \\
\text { Literal, pour s'aprocher de mes intentions; } \\
\text { ie feray bien glorieux, fi ie puis perfuader à } \\
\text { nos Dames, ce que cette belle Lesbienne, } \\
\text { perfuadoit à fon Amie: \& plus encore, fi ie } \\
\text { puis perfuader à toute la terre, que ce beau } \\
\text { Sexe, eft digne de noftre adoration: afin }\end{array}$ & $\begin{array}{l}\text { Não se pode dizer que esta arenga não teve } \\
\text { nenhum efeito, se tomarmos as palavras ao } \\
\text { pé da letra, pois parece que aquela a quem } \\
\text { esta arenga se endereçava seguiu a direção } \\
\text { desejada, já que um epigrama grego nos } \\
\text { disse que tanto Safo superou Erina em } \\
\text { poesia lírica quanto Erina superou Safo em } \\
\text { versos hexâmetros. Mas se nos afastamos do } \\
\text { sentido literal para considerar minhas } \\
\text { intenções, ficaria muito satisfeita se tiver } \\
\text { conseguido instigar nossas damas da mesma } \\
\text { forma que essa admirável lesbiana }{ }^{8} \text { instigou } \\
\text { sua querida amiga e ficaria mais ainda se } \\
\text { tiver instigado o mundo a enxergar que esse } \\
\text { fascinante sexo é digno de nossa adoração }\end{array}$ \\
\hline
\end{tabular}




\begin{tabular}{|l|l|}
\hline qu'on luy confacre vn iour des Temples \& & para que um dia templos e altares sejam \\
des Autels, comme ie luy confacre & consagrados às mulheres, tal como agora \\
maintenant, L'ARC DE TRIOMPHE, QVE & consagro-lhes O ARCO DO TRIUNFO \\
I'AY ESLEVE A SA GLOIRE. & ERGUIDO À SUA GLÓRIA ${ }^{9}$. \\
\hline
\end{tabular}

\section{REFERÊNCIAS}

CASTRO, Olga. (Re)examinando horizontes nos estudos feministas de tradução: em direção a uma terceira onda?. Tradterm, São Paulo, v. 29, p. 216-250, 2017. Disponível em: http://www.revistas.usp.br/tradterm/article/view/134563/130370. Acesso em: 5 jan. 2020.

GARCIA, Carla Cristina. Breve história do feminismo. 3 ed. São Paulo: Claridade, 2011.

LEFEVERE, André. Translation / history / culture: a sourcebook. London; New York: Routledge, 1992.

SCUDÉRY, Madeleine. Les femmes illustres, ou Les harangues hérö̈ques [de Mr de Scudéry : avec les véritables portraits de ces héroïnes, tirez des médailles antiques]. Paris: Antonin de Sommaville e Augustin Courbé, 1642, p. 422-442. Disponível em: https://gallica.bnf.fr/ark:/12148/bpt6k109257n.image. Acesso em: 7 dez. 2019.

* André Luís Leite de MENEZES - Mestrando em Estudos da Tradução e Graduado em Letras Francês (2018)
pela Universidade Federal de Santa Catarina.
Florianópolis, Santa Catarina, Brasil.
Currículo acadêmico: http://lattes.cnpq.br/9572666418292946
ORCID: https://orcid.org/0000-0001-8882-0166
E-mail: andreluisleite13@ gmail.com

** Marie-Hélène Catherine TORRES - Doutora em Estudos em Tradução (2001) pela Katholieke Universiteit Leuven, Bélgica. Mestre em Literatura Brasileira (1995) e graduada em Português/Francês (1992) pela Universidade Federal de Santa Catarina. Realizou pesquisa de pós-doutorado na Université Bordeaux Montaigne (2019), França, com bolsa do CNPq, e na Universidade Federal de Minas Gerais (2011-2012), Brasil. É professora titular na Universidade Federal de Santa Catarina.

Florianópolis, Santa Catarina, Brasil.

Currículo acadêmico: http://lattes.cnpq.br/1477390958277483

ORCID: https://orcid.org/0000-0001-9263-0162

E-mail: marie.helene.torres@gmail.com

${ }^{1}$ É importante mencionar o site https://mnemosineantologias.com/seculo-xviii/, que desde 2015 reúne traduções em português de textos de autoras francesas do século XVII e XVIII, contribuindo enormemente para a divulgação de uma série de obras de autoria feminina ao público-leitor brasileiro.

${ }^{2}$ GIOVANNI, Ricciardi. Auto-retratos. São Paulo: Martins Fontes, 1991.

${ }^{3}$ Essas e outras questões são exploradas e analisadas por John M. Conley em seu verbete dedicado à vida e obra de Madeleine de Scudéry, publicado em 2011 pela Stanford Encyclopedia of Philosophy, editada por Edward N. Zalta. Disponível em: https://plato.stanford.edu/entries/madeleine-scudery/. Acesso em: 11 dez. 2019.

${ }^{4}$ Disponível em: https://www.dictionnaire-academie.fr/article/A9H0164. Acesso em: 30 jul. 2019.

${ }^{5}$ As traduções consultadas aparecem nas seguintes obras: The Story of Sapho, publicada em 2003, com tradução de Karen Newman, e em Selected Letters, Orations, and Rhetorical Dialogues, publicada em 2004, editada e traduzida por Jane Donawerth e Julie Strongson — ambas publicadas pela University of Chicago Press como parte de uma série dedicada a escritoras do início do período moderno.

${ }^{6} \mathrm{Na}$ mitologia romana, Mercúrio é o deus da eloquência, da arte de falar bem, e Apolo, o deus da poesia, ao passo que Minerva é a deusa da sabedoria e das artes, e as musas eram encarregadas de proteger as Artes, as Letras e as Ciências. Dentre as diversas obras sobre mitologia greco-latina, recomenda-se Mitologia Grega e Romana, de Pierre Commelin, traduzida para o português por Eduardo Brandão e publicada no Brasil em 2011, pela editora Martins Fontes. 
7 Trata-se do Monte Parnaso, montanha sagrada na Grécia antiga destinada a Apolo e às nove musas.

${ }^{8}$ Do francês lesbienne, relativo à Ilha de Lesbos.

9 Durante o Renascimento, era comum a construção de arcos nas cidades para celebrar feitos políticos ou comemorar importantes personalidades. 